\title{
TU/e EmonONEN

\section{Target setting for the departments in an aircraft repairable item system}

Citation for published version (APA):

Haas, de, H. F. M., \& Verrijdt, J. H. C. M. (1997). Target setting for the departments in an aircraft repairable item system. European Journal of Operational Research, 99(3), 596-602. https://doi.org/10.1016/S03772217(96)00323-2

DOI:

10.1016/S0377-2217(96)00323-2

Document status and date:

Published: 01/01/1997

\section{Document Version:}

Publisher's PDF, also known as Version of Record (includes final page, issue and volume numbers)

\section{Please check the document version of this publication:}

- A submitted manuscript is the version of the article upon submission and before peer-review. There can be important differences between the submitted version and the official published version of record. People interested in the research are advised to contact the author for the final version of the publication, or visit the $\mathrm{DOI}$ to the publisher's website.

- The final author version and the galley proof are versions of the publication after peer review.

- The final published version features the final layout of the paper including the volume, issue and page numbers.

Link to publication

\section{General rights}

Copyright and moral rights for the publications made accessible in the public portal are retained by the authors and/or other copyright owners and it is a condition of accessing publications that users recognise and abide by the legal requirements associated with these rights.

- Users may download and print one copy of any publication from the public portal for the purpose of private study or research.

- You may not further distribute the material or use it for any profit-making activity or commercial gain

- You may freely distribute the URL identifying the publication in the public portal.

If the publication is distributed under the terms of Article 25fa of the Dutch Copyright Act, indicated by the "Taverne" license above, please follow below link for the End User Agreement:

www.tue.nl/taverne

Take down policy

If you believe that this document breaches copyright please contact us at:

openaccess@tue.nl

providing details and we will investigate your claim. 


\title{
Target setting for the departments in an aircraft repairable item system
}

\author{
Harrie F.M. de Haas * , Jos H.C.M. Verrijdt \\ Eindhoven University of Technology, Faculty of Technology Management, Paviljoen F 16, P.O. Box 513, 5600 MB Eindhoven, The \\ Netherlands
}

\begin{abstract}
In this paper a repairable item system for the maintenance support of a fleet of aircraft is introduced. The purpose of the system, a complex conjunction of repair departments and stock locations, is the repair and supply of serviceable engines to the maintenance process of the aircraft. The performance of the repairable item system is measured by a service level. If the realized service level corresponds with the required service level, conditions are created among which the maintenance process can be carried out efficiently. Thus the setting of service levels is a means for the control of the repairable item system. To meet the required service level target for the entire repairable item system, it is important that the performance of the individual repair departments and the stock locations of the repairable item system are tuned. In this coordination process, service level targets must also be set for the repair departments and stock locations. In this paper it is show that the deduction of these service level targets can be supported with the help of well-known models such as METRIC and MOD-METRIC. In a numerical analysis it is shown that the targets for the repair departments can be substantially lower than the targets for the downstream stock locations of the repairable item system. (C) 1997 Elsevier Science B.V.
\end{abstract}

Keywords: Production control; Repairable item; Service level

\section{Aircraft repairable item system (ARIS)}

The motive for this paper is a case study carried out in cooperation with an airline in the Netherlands. The airline operates a fleet of aircraft for the transport of passengers and cargo. During aircraft maintenance, the condition of the jet-engines is compared to a set of safety norms. When the condition of a jet-engine is not in accordance with the norms, it is termed failed. Failed engines are replaced from stock by serviceable ones. Failed engines are sent off for

\footnotetext{
* Corresponding author.
}

repair to a specialized repair facility. When a repair is completed the, then serviceable, engine is stored at one of the main airports in support of a future engine replacement.

A jet-engine is a complex multi-indenture item. It consists of a number of modules which in turn consist of a number of parts. For the repair of the engines, the modules and the parts, the repair facility comprises of three hierarchically ordered repair departments: 'engine repair', 'module repair' and 'parts repair'. In the engine repair department the engines are inspected, dismantled, assembled and tested. The failed modules are replaced by serviceable modules from stock. The failed modules are transferred to the module repair department. There they are dismantled 
into parts, assembled and tested. The failed parts are replaced by serviceable parts and after that the, then serviceable, module is added to the module stock. The failed parts are cleaned and the repair requirements are determined. After that they are repaired in the parts repair department and added to the parts stock. The goods flow is depicted in Fig. 1. The conjunction of repair departments and stock locations we term the aircraft repairable item system (ARIS).

The ARIS on hand is characterized by a great level of uncertainty. First, there is uncertainty in demand in the short term. Failures occur with a low rate, irregularly and cannot accurately be predicted in the short term. Secondly, there is uncertainty in the work content of a repair. Detailed information becomes available only after parts have been cleaned and inspected. As a result of this uncertainty control is not straight forward and, consequently, a popular topic for research.

Issues regarding the control of ARISs are regularly addressed in the literature. In these studies the ARIS is generally considered a network of stock locations in which each stock location can be controlled by a continuous review $(S-1, S)$ policy. After the serviceable stock for an item has dropped below stock level $S$, a replenishment order is created. Because of the low demand rate and high cost of repairable items, the occurrence of a demand for a repairable item immediately triggers a replenishment order for that item. The demand process for repairable items is usually assumed to be (compound) Poisson distributed, since this distribution most adequately represents the irregular failure processes of complex technical systems. The vast body of the literature concerns the determination of optimal stock levels with respect to some service level. Most notable are the models of the METRIC family. Our interest is in METRIC, the purpose of which is the

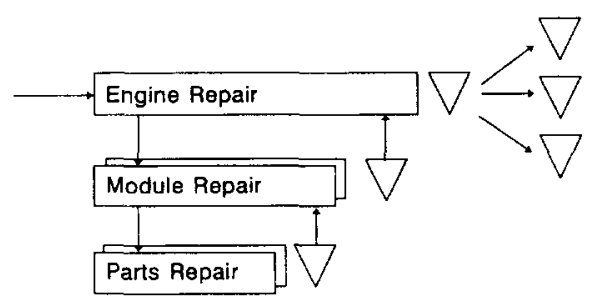

Fig. 1. Aircraft repairable item system. determination of engine stock levels in a divergent system (Sherbrooke, 1968) and in MOD-METRIC, the purpose of which is the determination of module and parts stock levels in a convergent system (Muckstadt, 1973). Both METRIC and MOD-METRIC frequently have been the subject of further study in recent years. For an excellent overview of the models of the METRIC family we refer to Sherbrooke (1992).

A periodic review $(S-1, S)$ control policy similar to METRIC was installed at the ARIS on hand. The METRIC model, as well as other related continuous review $(S-1, S)$ models such as MOD-METRIC (Muckstadt, 1973) and VARI-METRIC (Graves, 1985), implicitly assume that (repair) capacity is unlimited. In practice, however, repair capacity is clearly limited and the periodic review replenishment policy did not satisfy the management of the ARIS. The replenishment policy directly transposed demand into repair orders. This control procedure, in combination with an irregular demand pattern, results in an irregular release of repair orders. High work loads took turns with low work loads. In fact the repair departments were having to deal with the irregular demand and the consequences of this, such as the occurrence of frequent overtime and stress upon the repair men. In order to overcome these problems it was decided that more attention had to be paid to the capacity aspect in their planning and control system.

A control approach for ARISs that does pay attention to this capacity aspect is presented by De Haas (1995). He proposes to decompose the downstream stock locations and repair departments into more or less independent organisational departments i.e. stock locations and repair departments. For the structural and operational control of these organisational departments, a hierarchical framework for control is designed which consists of three decision levels. At the highest level, targets are formulated for the organisational departments. At the middle level, control parameters are determined for each repair department. With the help of these control parameters the repair departments can be operationally controlled at the lowest repair department. The main ideas of this approach are summarized in Section 2 of this paper. Hence, in Section 3 we focus on the highest level of control, i.e. the structural coordina- 
tion, and show how METRIC and MOD-METRIC can be helpful in the formulation of targets for the repair departments and the stock locations. We present a model to support the formulation of targets for the ARIS on hand. In a numerical analysis with this model in Section 4, we show how targets evolve under different conditions for the ARIS. In Section 5 , finally, we discuss the consequences of the analysis for the control of the ARIS on hand.

\section{Framework for control}

In our view, control is the coordination of activities that have the purpose to buffer against (the variations in) demand and repair throughput time in order to achieve a target at minimum cost. The coordination of the activities is accomplished by a set of decisions, made by managers at different hierarchically ordered levels in an organization. The relation between these decisions is visualized in a framework for control.

In our definition of control we explicitly mention the minimization of costs. Cost minimization requires the simultaneous consideration of all decisions bearing an important cost aspect, thus stock control decisions as well as capacity decisions. We therefore advocate that the important cost factors should be considered at one decision level in the framework irrespective of their repetition frequency and operational duration. At this level alternatives for the control of the ARIS are evaluated on costs subject to a target constraint. The target constraints are formulated by the management on a higher level in the organization. The evaluation yields a favourable alternative. The directives regarding the stock control and capacity control, corresponding with the selected alternative, are handed over to the next lower decision level where the operational control is executed.

The alternatives could in principle be evaluated with the help of a detailed monolithic mathematical model of the ARIS. However, such an approach would have two disadvantages. First, from a mathematical point of view, the construction of a detailed model which accounts for the main characteristics of the entire ARIS would be an extremely complex task. Rather we would construct a number of simple loosely connected models. Secondly, the responsibil-

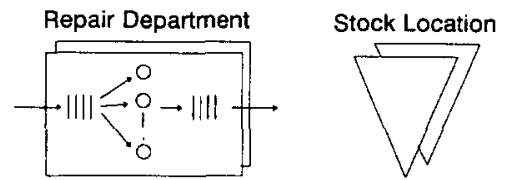

Fig. 2. Organisational departments.

ity for decision-making within the ARIS is spread over a number of organizational departments. If all managers of these departments would be supported with only one model, then they would be jointly responsible for the realized performance for the entire ARIS. When deviations between the realized and target performance occur, it is not difficult to imagine that they would be easily inclined to seek for explanations in one another's organisational department. In other words, the derivation of directives with the help of a single monolithic model would not fit the organizational structure of the ARIS. Rather we construct a model, define a target and measure a service level, for each organizational department. These targets are not mutually independent. They should be deduced from a management goal with the help of an approximate mathematical model.

The ARIS is a very complex system due to the existence of many related stock locations and repair departments. To reduce this complexity we decompose the system into a number of loosely connected self-empowered stock locations and repair departments, see Fig. 2. In our view the central engine stock (depicted by a queuing symbol) is part of the engine repair department, the module stock is part of the module repair department and the parts stock is part of the parts repair department. The control decisions for these stock locations and repair departments are recorded in the framework for control, see Fig. 3. It comprises of three hierarchically ordered decision levels: at the highest level, target coordination; at the middle level, structural control and at the lowest level, operational control.

At the target coordination level, targets for the individual stock locations and repair departments are determined. These targets are deduced from a management goal with the help of a mathematical model. In addition to the targets, (serviceable) stock replenishment levels are deduced for the individual stock locations. On the basis of these replenishment levels the stocks with serviceable engines, modules and 


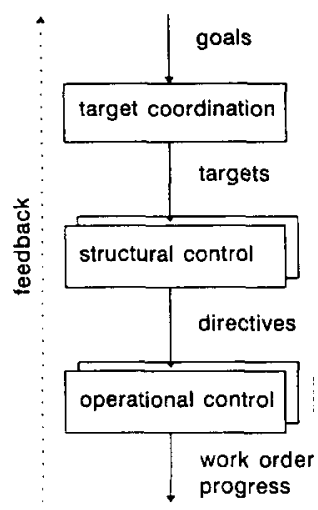

Fig. 3. Framework for control.

parts can be operationally controlled. The targets are input for the structural control of each distinct repair department within the ARIS.

At the structural control level the various alternatives to achieve the target are evaluated on the basis of cost and practical motives for each repair department individually. The alternatives vary with respect to the size and the composition of the stocks, the capacity level, the priority rule to schedule failed units into repair and the overtime policy. The proposed stock and capacity levels are fed back for approval to the management that is responsible for the target coordination level. The selected priority rule and overtime policy are passed on to the management responsible for the operational control of the repair department.

At the operational control level work orders are dispatched to the repair department with the help of the priority rule. The progress of the work orders within the repair department is controlled by internal due dates. The repair men are allocated to the repair work. The lengths of the working days are controlled by the overtime planning function. The lengths of the working days are determined by a comparison of the overtime policy with the actual work in process.

Regular feedback of information is important to improve the process of control. Information with respect to the realized performance by the organisational departments must be fed back to the management that is responsible for the target coordination of the entire ARIS. Information regarding the realized service levels, the stock levels, the capacity levels and the overtime must be fed back to the managers that are responsible for the structural control of the departments. Finally, information regarding the speed and quality of the repairs must be fed back to the management that is responsible for the operational control of the departments.

\section{Target setting model}

The management goal for the ARIS is formulated in rough terms i.e. 'We must realize a $95 \%$ service level to our customer'. This goal statement is not precisely defined and therefore not suitable to serve as a target for control. Before presenting more accurate definitions we introduce the following variables:

- The initial stock level for item $j$ is $S_{j}, S_{j} \geq 0$, $1 \leq j \leq J$.

- The steady state probability of $x$ failed units of item $j$ is $p_{j}(x), 0 \leq p_{j}(x) \leq 1, \sum_{p_{j}}(x)=1, x \geq$ $0,1 \leq j<J$.

- The service level for item $i$ is $f_{j}, 0 \leq f_{j} \leq 1$, $1 \leq i \leq J$.

- The target for a department is $f, 0 \leq f \leq 1$.

- The expected demand for item $j$ per day is $\lambda_{j}$, $\lambda_{j}>0, \lambda=\sum_{j} \lambda_{j}, 1 \leq j \leq J$.

We define the service level for an item as 'the percentage of demand for an item that can be met immediately from stock on hand, i.e.

$f_{j}=100 \sum_{x=0}^{s_{j}-1} p_{j}(x)$

We define a target for a department as a weighting of all item service levels with respect to their expected demand rates, namely

$f=\sum_{j=1}^{J} \frac{\lambda_{j}}{\lambda} \cdot f_{j}$

These definitions are formulated in deliberation with the higher management of the ARIS. Note that the $95 \%$ service level requirement in this example refers to the required performance for the downstream engine stock locations that supply the customers with spare engines. It is by no means a performance requirement for the central stock location and the repair departments. In the target coordination, targets for the engine stock locations and the repair departments are deduced from the roughly 
formulated goal statement. The deduction can be supported by mathematical models which approximately represent the behaviour of the entire ARIS. Such approximate models are the models METRIC and MOD-METRIC that were developed at the RAND corporation in the seventies and implemented in the US air force. These models were developed for the determination of stock replenishment levels for items at the various stock locations such that the number of expected back orders at the downstream engine stock locations were minimized, subject to a budget constraint. METRIC calculates stock replenishment levels for the repairable engines. MODMETRIC takes account of the hierarchical product structure and also calculates stock replenishment levels for the modules and parts.

METRIC and MOD-METRIC are approximate representations of reality in their assumption of unlimited capacity. This assumption implies that repair times are independent and that waiting times for repair do not occur. The assumptions enable the application of Palm's theorem (Palm, 1938). The theorem states that "the number of items under repair in a $\mathrm{M}|\mathrm{G}| \propto$ queue is Poisson distributed with a mean equal to the product of the mean demand rate and the mean repair time". In other words, the performance of the ARIS is only affected by the mean repair time and not by the repair time distribution itself MOD-METRIC is approximate in assuming that an engine failure is caused by only one module and that a module failure is caused by only one part. As a result of these assumptions, both models tend to slightly over-estimate the service level of an ARIS (Gross, 1982). However, for an approximate formulation of long-term service level targets these models serve our purpose.

Both METRIC and MOD-METRIC were developed for an ARIS that was more complex than the one in Fig. 1 in having additional repair facilities attached to each downstream stock location. Demand was further assumed to behave according to a compound Poisson process. In the ARIS on hand there is only one repair facility attached to the central engine stock location. The demand rates at the downstream stock locations are assumed to be Poisson distributed. Both deviations are accounted for in METRIC and MOD-METRIC. Hence we illustrate how targets can be deduced from a goal with the help of
METRIC and MOD-METRIC. For the formalization of this routine we introduce the following variables: Metric:

$N: \quad$ the number of downstream stock locations.

$B$ : the target over all downstream stock locations.

$E\left(f_{i}\right): \quad$ the expected service level at downstream stock location $i, i=1, \ldots, N$.

$\lambda_{i}$ : he Poisson demand rate at stock location $i$.

$S_{i}: \quad$ the stock level at stock location $i$.

$S_{0}$ : the stock level at the central stock location.

$D: \quad$ the average repair time at the central stock location.

$L_{i}$ : the transshipment time from the central stock location to stock location $i$.

$T_{i}: \quad$ the expected replenishment time for an engine at stock location $i$ (note that $T_{i}$ depends on $L_{i}, S_{0}$ and $D$ ).

$p\left(x \mid \lambda_{i} T_{i}\right)$ : the Poisson probability of $x$ end-items in resupply at stock location $i$.

$C$ : the unit cost for an end-item.

Mod-metric:

$\delta$ : the target number of backorders at the central stock location.

$E\left(b_{0}\right): \quad$ the number of expected backorders at the central stock location.

$\lambda$ : the Poisson demand rate for engines at the central stock location, $\lambda=\sum_{i} \lambda_{i}$.

$p$ : $\quad$ the probability that module $j$ (or part $k$ in module $j$ ) is failed.

$R . \quad$ the average repair time for the end-item, module $j$ (or part $k$ in module $j$ ).

$S_{0}^{*}: \quad$ the initial stock level for an engine at the central stock location.

$S_{j}^{*}: \quad$ the initial stock level for module $j$.

$S_{j k}^{*}$ : the initial stock level for part $k$ in module $j$.

$T_{0}$ : the replenishment time for an engine (note that $T_{0}$ depends on $S^{*}, R$. and $p$.).

$C_{j}$ : the unit cost for module $j$.

$C_{j k}$ : the unit cost for part $k$ in module $j$.

In our application of METRIC we calculate the engine stock levels with the help of a marginal allocation procedure that minimizes expected backorders at the downstream stock locations. The stock 
levels are increased until the target service level over all downstream engine stock locations, weighted by their demand rates, is obtained. When these engine stock levels are substituted in Eqs. (1) and (2), targets for the engine repair department and downstream stock locations are obtained.

In our application of MOD-METRIC we calculate the part-, module- and engine central stock levels with the help of a marginal allocation procedure that minimizes expected back orders of engines at the central engine stock location. The allocation procedure is similar to the one described in our application of METRIC. When the module and part stock levels are substituted in Eqs. (1) and (2), targets for the module and parts repair department are obtained. The targets for the organisational departments of the ARIS can now be obtained in a simple two step routine.

Step 1: An overall target $B$, determined at a high management level in the organization, is used as an input parameter in the METRIC model. The METRIC model determines the optimal engine stock levels such that $B$ is attained most economically. On the basis of these stock levels we derive demand weighted service levels for the engine repair department. These demand weighted service levels serve as targets for the management that is responsible for the structural control of the engine repair department. On the basis of the central engine stock level we derive the expected number of back orders and denote this measure $\delta . \delta$ is used as an input parameter in the MOD-METRIC model.

Step 2: The MOD-METRIC model determines the optimal stock levels for the engines at the central stock location, modules and parts such that $\delta$ is attained most economically. On the basis of these stock levels we determine demand weighted service levels. These weighted service levels serve as targets for the management that is responsible for the structural control of the module and parts repair department.

The model is part of an evaluation procedure for establishing cost effective alternatives. In this procedure the repair men initially operate under a high utilization. When the number of repair men increases, their utilization decreases and, as a consequence, the repair throughput times also decrease. New stock levels and targets are calculated, corre- sponding with this throughput time. When the number of repair men and the initial stock levels are incorporated into a cost function, an estimate of the structure costs is obtained. This procedure can be repeated a number of times. After some stopping criterion is met, for instance on the maximum number of repair men, the alternative with the lowest costs is selected. The targets associated with this alternative are imposed upon to the management of the repair departments. In a numerical illustration of the model we show how the targets evolve with different repair throughput times.

\section{Numerical illustration}

In this section we derive targets for the ARIS depicted in Fig. 1. The ARIS contains three downstream engine stock locations, one central stock location which is part of the engine repair department, a module stock location which is part of the module repair department and a parts stock location which is part of the parts repair department. The standard lead time for deliveries from the central engine stock location to the downstream stock locations is stochastic with a mean equal to one day. The target service level for the downstream engine stock locations is set at $95 \%$ by the highest level management of the ARIS. There is only one engine type, which is composed of two repairable modules. Each module is, in turn, composed of three repairable parts. The demand for an engine at downstream stock location $i$ is Poisson distributed with demand rates $\lambda_{1}$ engines per day: $\lambda_{1}=0.1$ (stock location 1), $\lambda_{2}=0.2$ (stock location 2) and $\lambda_{3}=0.3$ (stock location 3). A failure of an engine is caused by one module, with an equal probability for module 1 and module 2 . A failure of a module is caused due to a failure of only one part. A failure of module 1 (module 2 ) is caused with a probability of 0.25 by part 11 (part 21) or part 12

$\begin{aligned} & \text { Table } l \\
& \text { Settings of repair throughput times in the analysis }\end{aligned}$
\begin{tabular}{lllc}
\hline$D$ & $R_{0}$ & $R_{i}$ & $R_{i j}$ \\
\hline 10 & 2 & 2 & 6 \\
20 & 5 & 5 & 10 \\
30 & 7 & 7 & 16 \\
\hline
\end{tabular}


Table 2

Targets

\begin{tabular}{lllll}
\hline$D$ & DSL (\%) & ERD (\%) & MRD (\%) & PRD (\%) \\
\hline 10 & 95 & 61 & 34 & 52 \\
20 & 95 & 58 & 35 & 52 \\
30 & 95 & 47 & 35 & 62 \\
\hline
\end{tabular}

(part 22). It is caused with a probability of 0.50 by part 13 (part 23). The unit cost corresponds with 8 units for an end-item, 5 units for a module and 2 units for a part, thus the purchase of 'an engine in modules' is relatively more expensive than the purchase of 'an entire engine'. The purchase of 'a module in parts' is relatively more expensive than the purchase of 'an entire module'.

In the analysis we let the characteristics of the ARIS differ with respect to repair throughput times. The average repair time $D$ is set to the values: $D=10$ days, $D=20$ days and $D=30$ days. The total repair time $D$ is the sum of the engine repair time $R_{0}$, the module repair time $R_{i}$ and the parts repair time $R_{i j}$. For the individual repair times see Table 1.

For the situations in Table 1, the targets can be calculated with the two step routine, described in Section 3. The results are included in Table 2. The abbreviations in this table stand for: $D$ (repair throughput time), DSL (downstream stock locations), ERD (engine repair department), MRD (module repair department) and PRD (parts repair department).

The results in Table 2 indicate that the targets for the repair departments (engines, modules, and parts) are substantially lower than the external target of $95 \%$.

\section{Discussion}

In this paper we showed that targets for the distinct organisational departments in a ARIS can be determined with the help of well-known models in the literature. The results of the analysis show that targets are high for the stock locations closely situated to the aircraft. The repair departments further away from the aircraft can often suffice with much lower targets. The exact values of these targets depends on the parameter setting in the ARIS.

The targets resulting from this study were compared with the service levels that were realized by the repair departments in the ARIS under study. It appeared that the realized service levels were much higher i.e. close to $100 \%$. Apparently the foremen of the repair departments used all means to deliver all repair orders in time. Departmental due dates were obtained at the expense of stress and high overtime costs. These overtime costs have likely not resulted in a better up-time of the aircraft.

In the production control literature the focus is generally on the control of throughput times. Flexibility, for instance in the use of overtime, is generally not embedded in the control system. It is considered a managerial problem to deal with orders overdue. In fact these overdue occurrences do not always affect the performance that is realized to the customer. In that case the flexibility, a substantial cost factor, should be accounted for in the control systems to control the corresponding costs. In our view, further research is required into the effects and the embedding of various forms of flexibility in production control systems.

\section{References}

De Haas, H.F.M. (1995), “The coordination of initial stock and flexible manpower in repairable item systems", Ph.D. Thesis, Eindhoven University of Technology.

Graves, S.C. (1985), "A multi-echelon inventory model for a repairable item with one-for-one replenishment", Management Science 31, 1247-1256.

Gross, D. (1982), "On the ample service assumption of Palm's theorem inventory modelling", Management Science 28, 1065-1079.

Muckstadt, J.A. (1973), “A model for multi-item, multi-echelon, multi-indenture inventory system", Management Science 20, $472-481$.

Palm, C. (1938), "Analysis of the Erlang traffic formula for busy-signal arrangements", Ericsson Technics 5, 39-58.

Sherbrooke, C.C. (1968), "METRIC: A multi-echelon technique for recoverable item control", Operations Research 16, 122141.

Sherbrooke, C.C. (1992), Optimal Inventory Modelling of Systems: Multi-Echelon Techniques, John Wiley and Sons, New York. 